\title{
The Role of Real Estate Derivatives in Hedging Real Estate: An Empirical Analysis of the U.S. Commercial Market
}

\author{
Cem Berk $^{1}$ \\ ${ }^{1}$ Istanbul Arel University, İstanbul, Turkey \\ Correspondence: Assoc. Prof. Cem Berk, Ph.D., Turkoba Mahallesi, ErguvanSokak 26/K, 34537 \\ Tepekent/Büyükçekmece, İstanbul, Turkey. \\ Received: June 20, 2016 \\ Accepted: July 4, 2016 \\ Online Published: July 17, 2016 \\ doi:10.5430/ijfr.v7n4p168 \\ URL: http://dx.doi.org/10.5430/ijfr.v7n4p168
}

\begin{abstract}
Today, real estate today is used as an important investment vehicle owing to its many benefits, including diversification and ability to yield real returns. Real estate prices can be volatile in the short run, and therefore, investors need to hedge themselves to avoid negative returns. This problem is due to the systematic and unsystematic components of real estate risk. Systematic risk refers to risk that applies to all similar properties, while unsystematic risk refers to risk that applies only to the property that needs to be hedged. The systematic component of real estate risk can be mitigated by proper use of real estate derivatives, such as forwards, futures, options and swaps. These are instruments whose underlying asset is the index, which is composed of real estate in the region with a similar purpose as the property being hedged. This study examines some of the major benefits and difficulties of using real estate derivatives for hedging real estate, using data from the U.S. commercial real estate market, such as those from Ishares U.S. Real Estate Exchange Traded Fund, General Growth Properties Inc., Simon Property Group Inc., The Macerich Company, and Vornado Realty Trust. The daily data are from the period June 19, 2000 and August 24, 2015 , with 3,820 pieces of information for each variable. The study aims to investigate the statistical integration in the U.S. commercial real estate market, using Johansen's cointegration test. The research helps provide a better understanding of the real estate derivatives market and has important implications for academicians, practitioners, and policy makers.
\end{abstract}

Keywords: cointegration, derivative contracts, indexing, real estate, risk management

\section{Introduction}

Real estate is an important investment vehicle and is known to achieve real returns above inflation. Successful investment in real estate, however, requires adopting appropriate measures against the risks of holding real estate. Price risk occurs in real estate because the value of a property may change according to both national and regional trends. Risks also come with finalizing a good leasing contract, as well as with property management. The risk of receiving non-favorable financing also exists when the investment is highly leveraged.

Both commercial and residential real estate can be subject to price volatility. This risk can be categorized into either systematic risk or unsystematic. Systematic risk, assuming that the investor hedges herself/himself with real estate derivatives whose value is based on the local real estate market index, is the risk that can be applied to price changes in the area in which the real estate is located. This risk can be controlled by the proper use of real estate derivatives. On the other hand, idiosyncratic risk is the change in the price of real estate independent from the area and that has to be controlled by the investor.

Derivatives have been used for precious metals, energy, agricultural, and financial products. Using derivatives for the real estate industry is rather new, starting only in the last few decades. A derivative is an instrument whose value changes according to a change in the underlying property. Using derivatives is often more practical than trading real estate with high transaction costs because real estate exposure can increase/decrease with the use of real estate derivatives.

Real estate is a very unique investment vehicle, and its return is affected by factors that do not necessarily have a high correlation with macroeconomic variables or the real estate industry. If the risks regarding the real estate exposure need to be hedged, indexing is one of the most important factors that need to be considered. In the context of real estate derivatives, an index is the pool of real estate that serves as a benchmark for the underlying real estate. This pool is often specialized further according to property type and location. 
The real estate derivatives market is led by the United States and the United Kingdom but is still unavailable in many developed countries. The derivatives are available for taking or hedging exposure in real estate. The major instruments in this field are forwards, futures, options, and swaps, which are obligations, rights, or changes of cash flows for real estate.

Basis risk, a well-known phenomenon in international finance, is the risk of a difference in the value change between the asset to be hedged and the derivative itself. This risk occurs when the asset to be hedged and the derivative are not exactly the same. In the case of real estate, there is a considerable probability that the values of the real estate to be hedged and the underlying real estate index change differently. There is also the risk of liquidity, given that in certain situations, investors may have trouble finding a counterparty to take a position for the same index, time, and amount.

The remainder of this paper is organized as follows. Section 2 covers some of the important works in the real estate derivatives and indexing literature, while Section 3 presents the research methodology. Section 4 describes the data and presents some of the important results of the analysis. Section 5 presents some of the study's major implications, while Section 6 provides the final remarks.

\section{Literature Review}

Many investors are heavily exposed in real estate, and standard financial instruments offer a poor hedge. Most of the property derivatives available have been tailored to meet the needs of institutional investors. Based on Swiss property derivatives, Syz et al. propose index-linked mortgages tailored to retail consumers, focusing on how to stabilize net wealth and quantify the risk of mortgage default.

The accuracy of the index is related to the quality, credibility, and transparency of the underlying price index. An index-linked mortgage reduces the systematic risks of real estate in portfolios. Institutional investors can face real estate exposure without actually holding real estate. Mortgage providers may balance their position by providing property derivatives to institutional investors. Therefore, reliable indices for residential property are required. Reasonable structures of index-linked mortgages involve linkage of principal while interest payments are fixed or linkage of interest payments and principal is fixed (Syz et al., 2007).

Valente argues that there have been some recent efforts to develop indices that provide a basis for derivative products. These indices include Moody's/Real CPPI, a transaction-based approach to repeat sales technology. Other indices are S\&P and GRA/Charles Schwab, which use a weighted average methodology to create a transaction-based index, and REXX by Cushman \& Wakefield, Newmark Knight Frank, which developed an econometric model based on macroeconomic data and rents.

It is very probable that these indices can be biased because of changing credit patterns, especially for those who include small transactions, transactions that have a value of less than US\$15 million. Furthermore, the composition of the index, particularly the type of property and the location, determines the accuracy. Thus, any major index such as the NCREIF can be biased compared with a custom index that is adjusted for property type and location (Valente, 2008).

Chegut et al. examine the commercial real estate derivatives market in London by studying a new transaction-based quarterly real estate index for the period 1997 to 2011. London is the most developed real estate derivatives market outside the United States. The market seems to be affected from the crisis earlier than New York, and the correlation between the two markets is low.

The value of real estate has a direct impact on national wealth; in particular, its role as collateral is very important for economic growth. The primary uses of a transaction-based index are valuation, performance evaluation, and risk management. Transaction-based indices are used in only a few countries and often only for residential property. The success of implementing such an index relies on the liquidity of the market, without which a random error will signal higher volatility for the market (Chegut et al., 2013).

Baroni et al. study the transaction-based and valuation-based indices and test whether they are suitable for the derivatives market. The robustness of the price level, mean, and volatility is tested for two real estate price indices, using the database for the Paris residential market for the period 1982 and 2005. The impact of the index revision is non-negligible in estimating the index price level for both indices.

Revision is required when a change in method takes place or new data integration to past series. It is widely practiced for residential real estate indices such as $\mathrm{S} \& \mathrm{P} /$ Case-Shiller. Various methodologies can be used for the measurement of volatility for the indices, which is a concern for investors for the derivatives for which underlying determinant is the indices (Baroni et al., 2008).

Lecomte studies the risks in commercial real estate markets and the validity of real estate derivatives. Real estate is well-known for its idiosyncratic risk structure owing to heterogeneous assets traded in illiquid markets with 
asymmetric information. Some researchers argue that effective hedges for commercial real estate are unfeasible because of the lack of reliable indices, while others claim that markets for cash-settled derivatives should be established based on alternative indices such as hedonic price indices.

Therefore, one might argue that no existing model of derivatives can satisfactorily address real estate investors' hedging needs. In theory, property derivatives should be based on multi-factor models depending on real estate's fundamental risk structure. In practice, one can only consider hedging at an aggregate level, whereas real estate might require a molecular approach. Therefore, an improvement might be hedonic index-based derivatives or highly specific composite sub-index derivatives (Lecomte, 2007).

\section{Research Model}

The data are first tested to see whether they are stationary. The first unit root test that is conducted is the augmented Dickey-Fuller (ADF) test:

$$
\Delta \mathrm{R}_{\mathrm{t}}=\mathrm{b}_{0}+\mathrm{b}_{1}+\prod_{0}+\mathrm{R}_{\mathrm{t}-1}+\sum \prod_{\mathrm{i}} \Delta \mathrm{R}_{\mathrm{it}-1}+\mathrm{e}_{\mathrm{t}}
$$

Where $R t$ is the closing price at time $t$ and $\Delta R t$ is the change in the price of the real estate stock or fund traded (Dsouza \& Mallikarjunappa, 2015).

To test whether a long-run relationship exists between variables, a Johansen cointegration test is conducted. The number of cointegrating vectors can be tested with trace and maximum eigenvalue tests (Beag \& Singla, 2014):

$$
\begin{gathered}
\mathrm{J}_{\text {trace }}=-\mathrm{T} \sum \ln \left(1-\lambda_{\mathrm{i}}\right) \\
\mathrm{J}_{\max }=-\mathrm{T} \sum \ln \left(1-\lambda_{\mathrm{r}}+1\right)
\end{gathered}
$$

\section{Data Analysis}

The data used in this study are from participants in the U.S. commercial real estate market, namely the Ishares U.S. Real Estate Exchange Traded Fund (shortened to "ISHARES" for the study), which has exposure to U.S. real estate companies and REITs; General Growth Properties, Inc. (shortened to "GG"); Simon Property Group, Inc. (shortened to "SIMON" for the study); The Macerich Company (shortened to "MR"); and Vornado Realty Trust (shortened to "VORNADO"). The daily (workday) data are for the period June 19, 2000 and August 24, 2015. There are 3,820 pieces of information for each variable. The goal of the study is to investigate the statistical integration in the U.S. commercial real estate market.

Figure 1 provides graphical presentations of the data
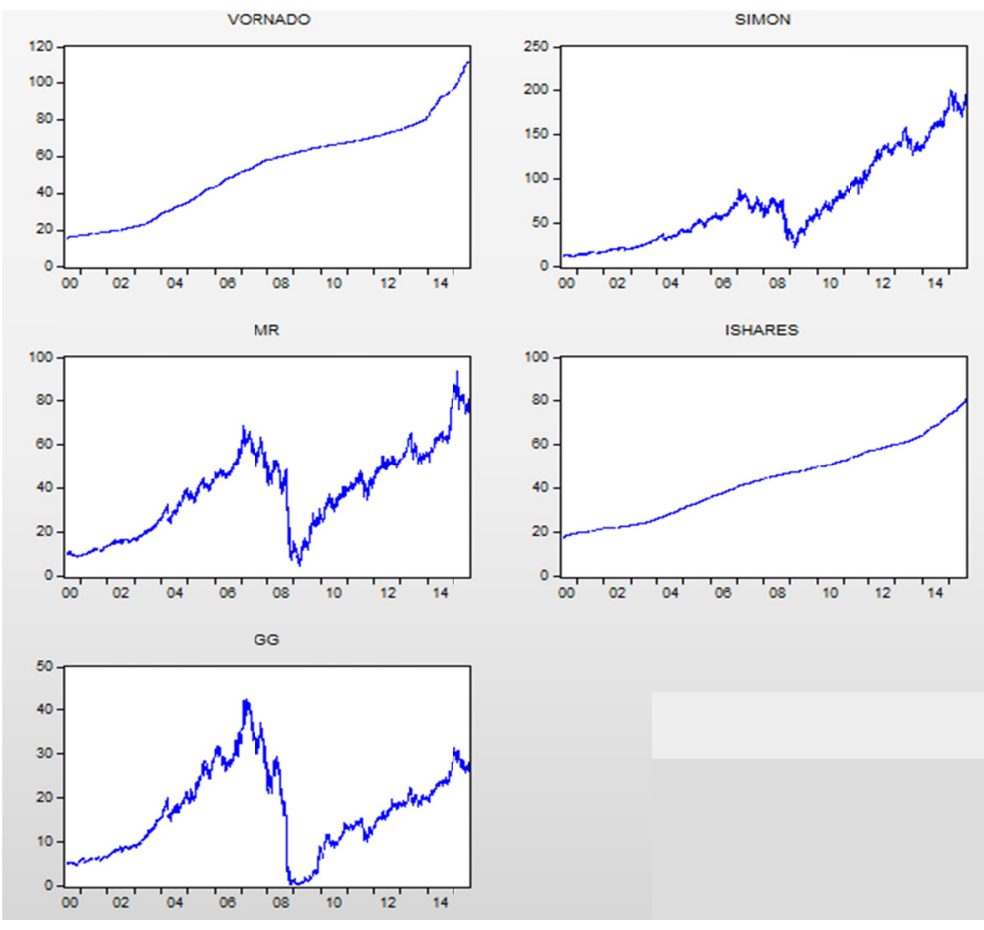

Figure 1. Graphical presentations of the data 
The variables are checked for whether they are stationary under a 5\% level of significance with the ADF methodology. The results are given in Table 1.

Table 1. ADF Test Results

\begin{tabular}{lcr}
\hline & $\begin{array}{c}\text { ADF TEST } \\
\text { STATISTIC }\end{array}$ & $\begin{array}{c}\text { CRITICAL } \\
\text { VALUE }\end{array}$ \\
\hline GG & $-1,9409$ & 0,0780 \\
\hline ISHARES & $-3,4110$ & 15,3670 \\
\hline MR & $-1,9409$ & 0,7966 \\
\hline SIMON & $-1,9409$ & 2,1935 \\
\hline VORNADO & $-3,4110$ & 12,5282 \\
\hline & & \\
\hline D(GG) & $-3,4110$ & $-62,6406$ \\
\hline D(MR) & $-3,4110$ & $-61,4262$ \\
\hline D(SIMON) & $-2,8621$ & $-71,1496$ \\
\hline D(VORNADO) & $-3,4110$ & $-48,9961$ \\
\hline D(ISHARES) & $-3,4110$ & $-52,0573$ \\
\hline
\end{tabular}

To test for the long-run relationship of the data, a VAR(1) model is developed. The model's stability is checked by examining unit roots. The results are given in Table 2.

Table 2. Results of Model Stability Check

Roots of CharacteristicPolynomial

Endogenousvariables: D(ISHARES) D(GG) D(MR)

D(SIMON) D(VORNADO)

Exogenousvariables: $\mathrm{C}$

Lagspecification: 11

Date: 09/01/15 Time: 09:40

\begin{tabular}{cc}
\hline \hline Root & Modulus \\
\hline \hline 0.343302 & 0.343302 \\
-0.163772 & 0.163772 \\
0.100371 & 0.100371 \\
0.050365 & 0.050365 \\
-0.048224 & 0.048224 \\
\hline \hline
\end{tabular}

No rootliesoutsidetheunitcircle.

VAR satisfiesthestabilitycondition. 
The VAR(1) model with the inserted coefficients is given below.

$$
\begin{aligned}
& \mathrm{D}(\text { ISHARES })=0.198273038711 * \mathrm{D}(\text { ISHARES(-1) })+0.00075893572727 * \mathrm{D}(\mathrm{GG}(-1)) \text { - } \\
& 0.00187802914105 * \mathrm{D}(\mathrm{MR}(-1))+0.000843364351144 * \mathrm{D}(\operatorname{SIMON}(-1))+0.0692474919561 * \mathrm{D}(\operatorname{VORNADO}(-1))+ \\
& 0.0117469344946 \\
& \mathrm{D}(\mathrm{GG})=0.00894614207389 * \mathrm{D}(\mathrm{ISHARES}(-1))-0.0404023946633 * \mathrm{D}(\mathrm{GG}(-1))+0.0385983845165 * \mathrm{D}(\mathrm{MR}(-1))- \\
& 0.01050890356 * \mathrm{D}(\operatorname{SIMON}(-1))-0.21628353859 * \mathrm{D}(\operatorname{VORNADO}(-1))+0.0108764619329 \\
& \mathrm{D}(\mathrm{MR})=-0.601293964552 * \mathrm{D}(\mathrm{ISHARES}(-1))+0.0262737302223 * \mathrm{D}(\mathrm{GG}(-1))+0.0643119469645 * \mathrm{D}(\mathrm{MR}(-1))- \\
& 0.0548561729436 * \mathrm{D}(\operatorname{SIMON}(-1))-0.0413850275657 * \mathrm{D}(\operatorname{VORNADO}(-1))+0.0292837552293 \\
& \mathrm{D}(\mathrm{SIMON})=-0.841706295607 * \mathrm{D}(\text { ISHARES}(-1))+0.0404408208979 * \mathrm{D}(\mathrm{GG}(-1))+0.0738881751706 * \mathrm{D}(\mathrm{MR}(-1)) \\
& -0.182353861645 * \mathrm{D}(\operatorname{SIMON}(-1))-0.619311275371 * \mathrm{D}(\operatorname{VORNADO}(-1))+0.0814734153252 \\
& \mathrm{D}(\text { VORNADO })=0.212883479752 * \mathrm{D}(\text { ISHARES(-1) })+0.00066016224624 * \mathrm{D}(\mathrm{GG}(-1))- \\
& 0.00251349178862 * \mathrm{D}(\mathrm{MR}(-1))+0.000578680531534 * \mathrm{D}(\operatorname{SIMON}(-1))+0.242212499878 * \mathrm{D}(\operatorname{VORNADO}(-1))+ \\
& 0.0157273078348
\end{aligned}
$$

The long-run relationship between the variables is tested with the Johansen's cointegration methodology. The results are given in Table 3.

Table 3. Cointegration Results

Date: 09/01/15 Time: 09:41

Sample (adjusted): 6/22/2000 8/24/2015

Includedobservations: 3816 afteradjustments

Trend assumption: Lineardeterministictrend

Series: D(ISHARES) D(GG) D(MR) D(SIMON) D(VORNADO)

Lagsinterval (in firstdifferences): 1 to 1

UnrestrictedCointegrationRank Test (Trace)

\begin{tabular}{ccccc}
\hline \hline $\begin{array}{c}\text { Hypothesized } \\
\text { No. of CE(s) }\end{array}$ & Eigenvalue & $\begin{array}{c}\text { Trace } \\
\text { Statistic }\end{array}$ & $\begin{array}{c}0.05 \\
\text { Critical Value }\end{array}$ & Prob.** \\
\hline \hline None * & 0.368094 & 6549.090 & 69.81889 & 1.0000 \\
At most $1 *$ & 0.339556 & 4797.490 & 47.85613 & 1.0000 \\
At most $2 *$ & 0.312124 & 3214.452 & 29.79707 & 1.0000 \\
At most 3* & 0.269253 & 1786.708 & 15.49471 & 1.0000 \\
At most $4 *$ & 0.143179 & 589.6729 & 3.841466 & 0.0000 \\
\hline \hline
\end{tabular}

Trace test indicates 5 cointegratingeqn(s) at the 0.05 level

* denotesrejection of thehypothesis at the 0.05 level

**MacKinnon-Haug-Michelis (1999) p-values

UnrestrictedCointegrationRank Test (Maximum Eigenvalue)

\begin{tabular}{lcccc}
\hline \hline Hypothesized & & Max-Eigen & 0.05 & \\
No. of CE(s) & Eigenvalue & Statistic & Critical Value & Prob.** \\
\hline \hline
\end{tabular}




\begin{tabular}{cllll} 
None & 0.368094 & 1751.600 & 33.87687 & 1.0000 \\
At most $1 *$ & 0.339556 & 1583.038 & 27.58434 & 0.0000 \\
At most $2 *$ & 0.312124 & 1427.744 & 21.13162 & 1.0000 \\
At most $3 *$ & 0.269253 & 1197.035 & 14.26460 & 1.0000 \\
At most $4 *$ & 0.143179 & 589.6729 & 3.841466 & 0.0000 \\
\hline \hline
\end{tabular}

Max-eigenvalue test indicates 5 cointegratingeqn(s) at the 0.05 level

* denotesrejection of thehypothesis at the 0.05 level

**MacKinnon-Haug-Michelis (1999) p-values

\section{Discussion}

The variables are first checked for whether they are stationary with the ADF test. The results show that the critical values fail to exceed test statistics in level. However, they exceed the level when they are first differenced, showing that all of the data are $\mathrm{I}(1)$.

A VAR(1) model is developed to check for the long-term relationship between the variables. The model is also tested for unit roots; the results show that no roots lie outside the unit circle, which means that the model is reliable. Finally, the variables are tested with the Johansen's cointegration methodology. Both the trace and max-eigenvalue suggest five cointegrating vectors, which indicates a long-run relationship between variables.

The results of the study show that U.S. commercial real estate market is statistically integrated, which suggests a potential to use real estate derivatives for hedging. In addition to its commercial and residential purposes, real estate is an important vehicle for investment. It generates real returns in the long run, albeit it can generate negative returns in the short run. Therefore, exposure to real estate needs to be hedged. This study gives a comprehensive overview of the real estate derivatives market and helps improve the understanding of market dynamics. The findings of the study have important implications for academicians, practitioners, and policy makers.

\section{Conclusion}

In addition to its commercial and residential purposes, real estate has been shown to be a reliable investment vehicle. It can yield real returns above the rate of inflation.

There are two types of real estate risk-systematic and unsystematic. Real estate is subject to price risk in the short term, and the volatility real estate prices can lead to negative returns. To control for the price volatility, real estate can be hedged with real estate derivatives.

Using real estate derivatives requires indexing based on property type and location. Since the value of real estate changes according to the changes in the index, systematic real estate risk, which is risk that applies to all similar properties, can be hedged. There is always unsystematic real estate risk, which comes from individual price changes of the property that remains unhedged owing to the idiosyncratic nature of real estate investment.

There are difficulties in using real estate derivatives for hedging real estate. One of the difficulties is basis risk, which is the possibility of asymmetrical change in the real estate index when compared with the property that is being hedged. This difficulty is due to the unsystematic risk in real estate. Another difficulty is creating an active secondary market for real estate derivatives. Without such a market, investors would have difficulty taking a position for the index they want at the amount and duration they want.

On the other hand, institutional investors may find it more practical to trade real estate derivatives than real estate itself because of the high transaction costs embedded in real estate. The exposure to real estate can be increased/decreased by taking a long or short position in real estate derivatives.

The most frequently used real estate derivatives are forwards, futures, options, and swaps which are obligations, rights, or changes in cash flow in an exchange or over-the-counter derivatives market. Such markets are most active in the United Kingdom and the United States, but more developed countries adopting them.

The application before the real estate derivatives market was trying to model real estate based on some macroeconomic factors and hedging real estate indirectly based on hedging these factors such as real estate. However, a true hedge for real estate should rely on an instrument based on real estate index itself. Some important efforts in 
building real estate indices include S\&P/Case-Shiller, GRA/Charles Schwab, Moody's/Real CPPI, REXX by Cushman \& Wakefield and Newmark Knight Frank, the NCREIF, and others. These efforts are extremely important because the applicability of real estate derivatives is determined by the strength of the underlying real estate index.

This study examines various benefits and difficulties in hedging real estate with real estate derivatives. It also empirically analyzes some large commercial real estate investors and a fund investing in U.S. real estate companies. The research helps academicians, practitioners, and policy makers get a better grasp of market dynamics and contributes to the literature. Future studies can extend our research by using real estate market and various index data for different segments and locations in different countries.

\section{References}

Baroni M., Barthelemy F., \& Mokrane M. (2008). Is it possible to construct derivatives for the Paris residential market?. Journal of Real Estate Finance and Economics, 233-264. http://dx.doi.org/10.1007/s11146-008-9114-6

Beag, F. A., \& Singla N. (2014). Cointegration, Causality and Impulse Response Analysis in Major Apple Markets in India. Agricultural Economics Research Review, 27(2), 291. http://dx.doi.org/10.5958/0974-0279.2014.00032.9

Chegut, A. M., Eichholtz, P.M.A., \& Rodrigues, P. (2013). The London Commercial Property Price Index. Journal of Real Estate Finance and Economics, 588-590. http://dx.doi.org/10.1007/s11146-013-9429-9

Dsouza, J. J., \& Mallikarjunappa, T. (2015). Does the Indian Stock Market exhibit random walk?. Paradigm, 19(1), 8. http://dx.doi.org/10.1177/0971890715585197

Lecomte, P. (2007). Beyond Index-Based Hedging: Can Real Estate Trigger a New Breed of Derivatives Market?. Journal of Real Estate Portfolio Management, 345-351. http://dx.doi.org/10.15396/eres2007_323

Syz, J., Vanini, P., \& Salvi, M. (2008). Property Derivatives and Index-Linked Mortgages. Journal of Real Estate Finance and Economics, 23-34. http://dx.doi.org/10.1007/s11146-007-9071-5

Valente, J. (2008). Real estate derivatives: It's our "dot-com" time. Journal of Real Estate Portfolio Management, 14(1), 76-77. 